\title{
The Personal Health Network Mobile App for Chemotherapy Care Coordination: Qualitative Evaluation of a Randomized Clinical Trial
}

Victoria Ngo ${ }^{1}, \mathrm{PhD}$; Cynthia G Matsumoto ${ }^{1}$, MS; Jill G Joseph ${ }^{1}, \mathrm{MD}, \mathrm{PhD}$; Janice F Bell ${ }^{1}$, MN, MPH, PhD; Richard $\mathrm{J} \mathrm{Bold}^{2}$, MD; Andra Davis ${ }^{3}$, RN, MN, PhD; Sarah C Reed ${ }^{4}$, MSW, MPH, PhD; Katherine K Kim¹, MPH, MBA, PhD

${ }^{1}$ Betty Irene Moore School of Nursing, University of California, Davis, Sacramento, CA, United States

${ }^{2}$ Comprehensive Cancer Center, University of California Davis Health, Sacramento, CA, United States

${ }^{3}$ Washington State University College of Nursing - Vancouver, Vancouver, WA, United States

${ }^{4}$ Division of Social Work, California State University Sacramento, Sacramento, CA, United States

\section{Corresponding Author:}

Katherine K Kim, MPH, MBA, PhD

Betty Irene Moore School of Nursing

University of California, Davis

2450 48th Street, Suite 2600

Sacramento, CA

United States

Phone: 15107615461

Email: kathykim@ucdavis.edu

\section{Abstract}

Background: Cancer care coordination addresses the fragmented and inefficient care of individuals with complex care needs. The complexity of care coordination can be aided by innovative technology. Few examples of information technology-enabled care coordination exist beyond the conventional telephone follow-up. For this study, we implemented a custom-designed app, the Personal Health Network (PHN) - a Health Insurance Portability and Accountability Act-compliant social network built around a patient to enable patient-centered health and health care activities in collaboration with clinicians, care team members, caregivers, and others designated by the patient. The app facilitates a care coordination intervention for patients undergoing chemotherapy.

Objective: This study aimed to understand patient experiences with PHN technology and assess their perspectives on the usability and usefulness of PHNs with care coordination during chemotherapy.

Methods: A two-arm randomized clinical trial was conducted to compare the PHN and care coordination with care coordination alone over a 6-month period beginning with the initiation of chemotherapy. A semistructured interview guide was constructed based on a theoretical framework of technology acceptance addressing usefulness, usability, and the context of use of the technology within the participant's life and health care setting. All participants in the intervention arm were interviewed on completion of the study. Interviews were recorded and transcribed verbatim. A summative thematic analysis was completed for the transcribed interviews. Features of the app were also evaluated.

Results: A total of 27 interviews were completed. The resulting themes included the care coordinator as a partner in care, learning while sick, comparison of other technology to make sense of the PHN, communication, learning, usability, and usefulness. Users expressed that the nurse care coordinators were beneficial to them because they helped them stay connected to the care team and answered their questions. They shared that the mobile app gave them access to the health information they were seeking. Users expressed that the mobile app would be more useful if it was fully integrated with the electronic health record.

Conclusions: The findings highlight the value of care coordination from the perspectives of cancer patients undergoing chemotherapy and the important role of technology, such as the PHN, in enhancing this process by facilitating better communication and access to information regarding their illness.

(JMIR Mhealth Uhealth 2020;8(5):e16527) doi: $\underline{10.2196 / 16527}$ 


\section{KEYWORDS}

care coordination, continuity of patient care; oncology; chemotherapy; patient-centered care; mobile health; technology adoption

\section{Introduction}

\section{Background}

Cancer care in the United States is fragmented [1-5] and complex [6]. The management of therapies, such as chemotherapy, requires the coordination of multiple hospital services and outpatient clinics [7]. Care coordination has been identified as a promising strategy for improving health care quality $[8,9]$. Engaging health care teams to actively participate in care coordination can be beneficial to patients in areas of improving communication, building trust, and facilitating transitions in care $[10,11]$. Successful care coordination involves effective communication among patients, their family members, and their care providers [12,13]. Communication between cancer patients and their health care team members can affect important health care decisions [14-16]. Patients face challenges such as lack of effective ways to document their health information while at the clinic or when they are away from home and lack of access care-related information [17].

It has been suggested that technology can aid in care coordination [18,19]. However, most information technology-enabled care coordination interventions have primarily utilized telephonic contact with limited examples of telehealth $[9,20]$. With technologies in communication and computing that have improved rapidly over the past decade, mobile health (mHealth) has enabled the collection of data, encouragement of healthy lifestyle changes, and improved management of care, especially in underserved and remote areas $[21,22]$. Mobile apps developed for cancer treatment can facilitate patient and provider communication, help manage patient information, and provide education around treatment follow-up [23]. Some features that may support a person's confidence in their ability to manage their own care include calendars, logging symptoms, tracking medications, and taking notes as needed [17]. Although mHealth is promising, the specific benefits to cancer care coordination have yet to be evaluated.

\section{Objective}

The Personal Health Network (PHN), a personalized, electronic social network built around a patient for collaboration with clinicians, care team members, caregivers, and others designated by a patient, was designed to address the challenges of cancer care coordination [24]. The objective of this study was to understand the participants' experiences with PHN technology and to assess their perceptions of usability and usefulness of the PHN on care coordination during chemotherapy.

\section{Methods}

\section{Application Description}

The PHN care coordination mHealth app was developed by a multidisciplinary group of experts who reviewed features from the published literature, assessed prototype versions [24] and conducted a user-centered design study with an evaluation of usability among patients [25]. The app consists of a dashboard for viewing all components of the care plan, contact information for members of the care team, regular symptom assessment surveys and other validated instruments to collect data on health issues and patient-reported outcomes, a self-management library of curated health information in Web, print, and video formats, a calendar with space for open-ended notes/journaling, secure messaging, and multiparty video chat (Figure 1). 
Figure 1. The Personal Health Network app, top left, dashboard, top right, care team including health professionals and family caregivers, bottom left, symptom assessment and person-reported outcomes, bottom right, self-management library.
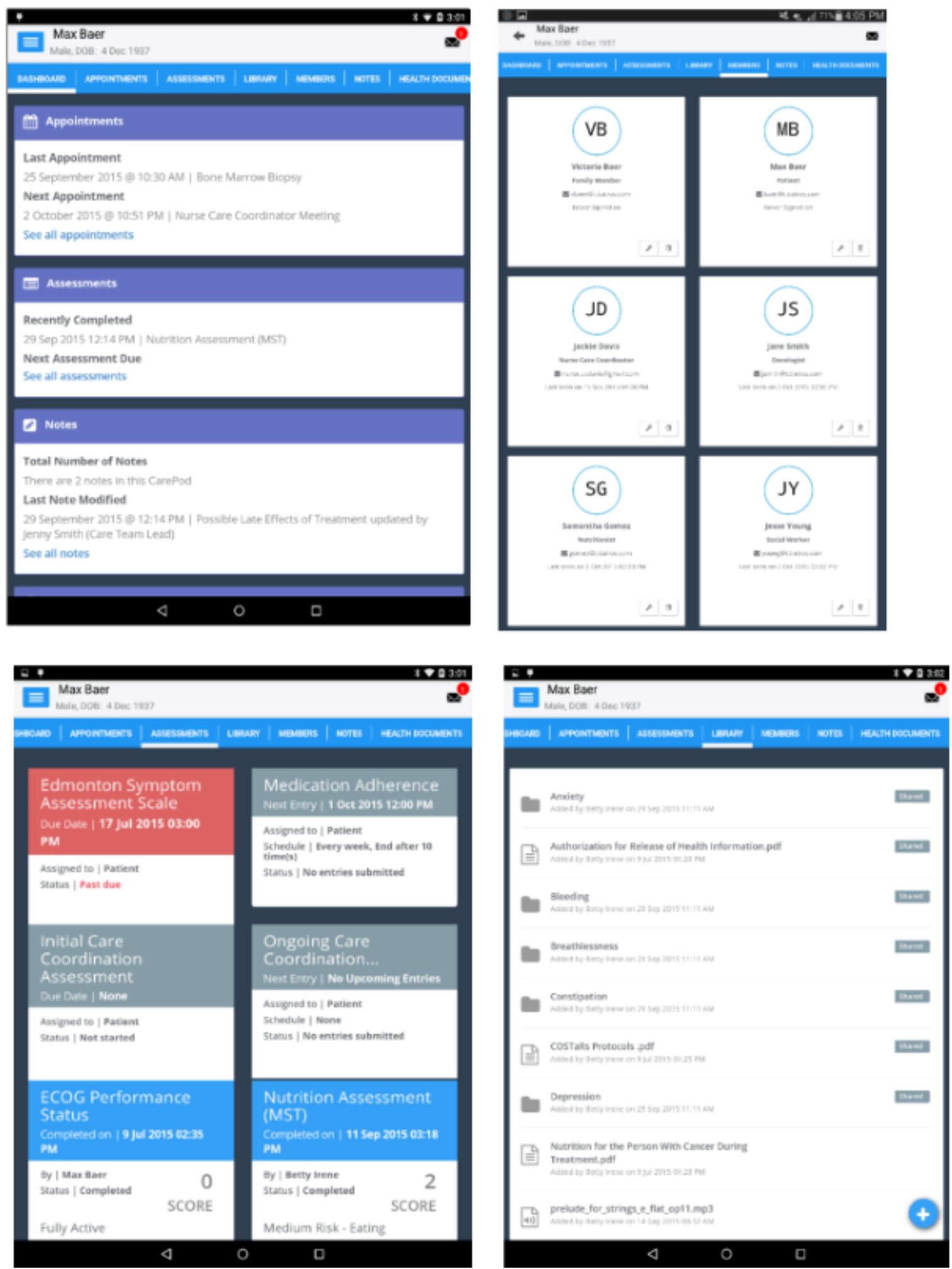

\section{Recruitment and Enrollment}

This study was a component of a small, two-arm ( $\mathrm{N}=63)$, randomized, pragmatic trial, in which the intervention group received the PHN technology and nurse care coordination, whereas the control group received nurse care coordination alone. Three registered nurses with care coordination training and experience provided care coordination to both arms. All

trial participants were English-speaking, over the age of 18 years, received care at an urban comprehensive cancer center, had a primary diagnosis of cancer (any site), were initiating chemotherapy and had an expected survival of at least six months. All participants were followed up for 6 months after enrollment. Those in the intervention arm received an 8.4-inch Samsung Galaxy tablet with Wi-Fi and 4G data plan (Galaxy Tab Pro 8.4 SM-T325 loaded with Android 4.4 Kitkat and 
TouchWiz UX software), and an individual orientation to the tablet and the PHN on enrollment. Technical assistance was embedded in the PHN app, and a telephone helpline was also made available. On study completion, all participants were allowed to retain the tablet. All participants in the intervention arm were asked to participate in the interviews. This study was approved by the Institutional Review Board of the University of California Davis. Written informed consent was obtained before data collection (trial registration: NCT02238951).

\section{Data Collection}

Interviewers used a semistructured interview guide based on concepts of the Unified Theory of Acceptance and Use of Technology [26], including usability and usefulness, impact on health, the experience of the participants using the PHN, usability of features, and barriers and facilitators to use. Interviews were conducted with the intervention-arm participants at 6 months or at the end of care coordination, whichever was earlier, recorded, and transcribed verbatim. Interviews were conducted by three individuals trained by a senior investigator who also reviewed recordings and discussed interview techniques to reinforce shared understanding and consistency among them.

\section{Data Analysis}

A two-phased thematic analysis method [27] was utilized: first, to identify the general themes and second, to review the themes identified in the context of usability and usefulness of the PHN app. NVivo 12 Pro (QSR International) was used to organize the data during the analysis. Two analysts (VN and CG) first familiarized themselves with the data by reading through the interview transcripts. They selected words and short phrases that symbolically evoked a salient attribute (ie, single idea codes) [27,28] and noted if the terms suggested positive, neutral, or negative sentiments. The researchers collaborated on the first two transcripts to develop a draft codebook, which was used for independent coding of the remaining transcripts. Any additions or revisions to the codes were discussed and added as needed. The analysts compared their coding and worked to align the differences found. Notations were made with analytic memos for discrepancies and changes in coding. Discrepancies between coders were resolved by a third researcher (KK). The three researchers conducted a final review of all the interviews to iteratively compare and discuss the patterns that were refined into themes based on discussion and consensus.

\section{Results}

\section{Participant Characteristics}

A total of 33 participants were randomized to the intervention arm of the underlying trial, and $82 \%$ (27/33) participated in interviews (Table 1). One participant passed away from the disease while enrolled in the study, and the rest declined being interviewed because of scheduling conflicts. The mean age was 59 years (range 22-79 years). Most participants were female $(23 / 27,85 \%)$ and white $(24 / 27,89 \%)$. The participants were highly educated (17/27, 63\% college graduates), and more than a third had high incomes $(10 / 27,37 \%$, had annual incomes $>$ US $\$ 80,000)$. 
Table 1. Characteristics of interview participants.

\begin{tabular}{|c|c|}
\hline Variables & Values, $\mathrm{n}(\%)$ \\
\hline \multicolumn{2}{|l|}{ Gender } \\
\hline Male & $4(15)$ \\
\hline Female & $23(85)$ \\
\hline \multicolumn{2}{|l|}{ Age (years) } \\
\hline 18 to 45 & $1(4)$ \\
\hline 46 to 64 & $15(56)$ \\
\hline 65 and older & $11(41)$ \\
\hline \multicolumn{2}{|l|}{ Race and ethnicity } \\
\hline Hispanic or Latino & $0(0)$ \\
\hline Non-Hispanic white & $24(89)$ \\
\hline Black or African American & $0(0)$ \\
\hline Asian & $2(7)$ \\
\hline Native Hawaiian or Pacific Islander & $1(4)$ \\
\hline \multicolumn{2}{|l|}{ Education } \\
\hline High school graduate or GED ${ }^{a}$ & $2(7)$ \\
\hline Some college & $8(30)$ \\
\hline College graduate & $6(22)$ \\
\hline More than 4-year college degree & $11(41)$ \\
\hline \multicolumn{2}{|l|}{ Income } \\
\hline Less than US $\$ 49,999$ & $7(26)$ \\
\hline US $\$ 50,000$ to US $\$ 79,999$ & $9(33)$ \\
\hline US $\$ 80,000$ and more & $10(37)$ \\
\hline Prefer not to state & $1(4)$ \\
\hline
\end{tabular}

${ }^{\mathrm{a} G E D}$ : general education diploma.

\section{Thematic Analysis of the Interviews}

A total of 82 single idea codes were generated and separated into positive and negative subgroups, resulting in 177 unique codes (13 codes were neutral). Key themes were uncovered through the systematic categorization of codes. In addition to overall usability and overall usefulness, 5 themes emerged from the data.

The 5 themes are listed below, and exemplar quotes are provided in Multimedia Appendix 1.

- Nurse care coordinator as a partner in care: this theme referred to someone who had a relationship with the patient, routinely checked in with the patient, helped find resources, communicated between team members, and assisted with problem solving;

- Learning: the learning theme refers to learning how to use a mobile app both via teaching and via experience using it;

- Learning while sick: participants gave insight on what it felt like to learn something new while going through chemotherapy, and for some, experiencing side effects from treatment;
- Comparison of other technology to make sense of the PHN: many participants made references to similar technologies, both apps, and devices, they used and how this knowledge was transferrable and helped them make sense of the PHN;

- Communication: the communication theme encompasses both access to people and information.

\section{Overall Usability}

Participants expressed that a usable app would be accessible through the internet, compatible with other apps (such as the electronic health record patient portal), easy to use, portable, navigable, and performed quickly. Some participants appreciated using the PHN because of access to information:

You know I never tried to manage my healthcare through PHN or even if I can pull MyChart into it or any of those things before. So it's all been a new and very good experience to always have access. The accessibility is just the best part of the whole thing. It's a 24/7 type thing.

The portability of the tablet and its ease of use allowed the participants to use the technology: 
And I know that when I came here for treatment and used it, I liked using it. It was you know very small, not heavy, so it's easy to carry with you. And like I said it's relatively easy to use too.

Connectivity to the internet was important:

I think everybody you know I think if you're going to push through with this program I think it'll be very helpful for all patients as long as they have access to Internet.

Not everyone found the app easy to use or usable because of the slow performance they experienced:

And I have very, very fast internet connections and things were sluggish and kind of kludgy. I know that's not a technological term but I was challenged and I'm looking at this thing going, this is literally driving me crazy. All this, you know, open up my laptop and go find this information quickly somewhere else.

Another participant said:

I know it's asking a lot but that was just my initial feel because I find the other technology so easy to use and I did not find that with the one that we were using from my care for the Project.

Due to some issues with usability and software upgrades, some participants felt discouraged from using the PHN:

And I'm trying to think back over the last 6-8 months since I've been using it and it just seems like it's just been really glitchy. And there has been a lot of changes so you know it seems like every time I was starting it up, I was looking at another update or another change.

And that's sort of what it felt like for me, it's like I mean I literally had to put on my glasses and to even see the font sizes and the buttons. And those are just navigational issues that I think that start that frustration where you go, I don't care what else is in here because I can't even get past the screen opening, or I can't do those kinds of things. And I think the organization of it was confusing and it didn't seem to make a whole lot of sense to me.

\section{Overall Usefulness}

Usefulness refers to the benefits of technology for participants to accomplish their health goals. Participants generally expressed that the PHN was useful because of the ability to answer questions beyond regular business hours. One person said:
It was helpful because it was on my time. So when I had to come up with a question at 7 o'clock at night when there's no one there and come 7 o'clock in the morning when I'm really running around doing something else and maybe not having the time to sit down and think about it at that moment I was able to ask my question whenever I wanted knowing I wasn't going to get a response till the next day but at least I wasn't, you know I was able to deal with it then before I forgot, before something else happened. So it's really-it's being able to do things on my time and my schedule.

Another participant mentioned that the PHN was helpful at the beginning of the chemotherapy journey, but not so much later:

Well, when I was really sick when I was in the beginning, I used to a lot more than I of course use now because I don't you know I'm not using it for the things that the nurse coordinator was dropping in for me and for that sort of stuff it was really, really useful.

As time progressed over a six month period I didn't use it as much. I didn't find it as useful because I wasn't searching out for those answers.

Another participant wanted more interaction with the PHN:

I was hoping it to be more interactive and more personalized to me as opposed to it was kind of generic, the information that was sent.

A suggestion mentioned was that the PHN might be useful for patients who require more support:

If I was in a situation where I needed more support it would have been really well, and so I think finding out how much support does the patient want and expect. Because I had the support at home, I had other things there I didn't feel that this was something that I needed but I can see where there are people that this would fill a gap in their care and I think it would be very well. And I'm probably not the best person to fully utilize the benefits that you have there.

\section{Usefulness of the Personal Health Network's Functions}

Overall, participants were more positive than negative regarding PHN functions. Table 2 shows the number of positive and negative comments made for each function. Participants identified ways in which these functions were useful to their overall health goals or specific needs related to chemotherapy care. Examples of usefulness are summarized in Multimedia Appendix 2. 
Table 2. Perception of the Personal Health Network by function.

\begin{tabular}{lllll}
\hline Function & Positive comments, $\mathrm{n}$ & Negative comments, $\mathrm{n}$ & Neutral comments, $\mathrm{n}$ & Total, $\mathrm{n}$ \\
\hline Library & 72 & 12 & 4 & 0 \\
Survey & 30 & 18 & 0 & 48 \\
Messaging & 34 & 11 & 0 & 45 \\
Camera & 1 & 6 & 19 & 7 \\
Calendar & 4 & 8 & 0 & 31 \\
Overall interface & 1 & 8 & 9 \\
\hline
\end{tabular}

\section{Discussion}

\section{Comparison With Prior Work}

As digital technology continues to develop and create more opportunities to provide health worldwide [29], the implementation of a digital health ecosystem-where the community health network of people, devices, and technology are interconnected-must take into consideration not only the interactions of technologies but also the network and interaction of key health care stakeholders both in receiving and providing care [30,31]. Especially in digital health ecosystems within the care and assistance domain, not all stakeholders are often invited to participate in the technology design process [32]. There have been few randomized controlled trials (RCTs) of mHealth in cancer care coordination described in the literature, and fewer still that involved clinicians and patients in the design and testing of the technology [33]. Before this study, the research team proposed a conceptual framework for person-centered, community-wide care coordination and defined the concept of point of need for coordination, which includes both settings where health care services are delivered and everyday settings where individuals need to make health-related decisions [9,34]. In addition, a user-centered design study of the PHN prototype investigated the usability of the platform to improve the design before starting the RCT [25].

\section{Principal Results}

The work presented in this paper investigates both usability and usefulness upon completion of care coordination among individuals undergoing chemotherapy. Similar to other studies $[33,35,36]$, our findings show that adults find mobile apps useful for monitoring symptoms and side effects, and as a way of communicating needs and coordinating care in a timely manner [37]. Although the literature on cancer care coordination activities in the United States is sparse [38], the themes that emerged from our summative interviews contribute viewpoints that can enhance future interventions and the design and implementation of mobile apps for this purpose.

An important aspect of care coordination is access to health information. Individuals with cancer and their caregivers want information about the illness, treatment options, care needs, and often turn to the internet to seek resources [15,39-41]. Individuals with cancer face challenges in managing their health-related information [17], which includes collecting relevant data, communicating about that data, and accessing informational resources to make sense of the data. There can be barriers to access, such as paywalls or membership-only portals [39]. Moreover, individuals may experience information overload, where synthesizing information becomes an obstacle $[42,43]$.

mHealth is well suited to facilitate information management tasks and may support health impacts [44]. The PHN, which was designed with these information management tasks in mind, was viewed as a supportive platform for accomplishing them. Although having the PHN was helpful for organizing information and care, the presence of a nurse care coordinator was important to help with problem solving. The PHN complemented the knowledge and experience of a nurse care coordinator to help guide, organize, and tailor information. The PHN library feature, in particular, received a substantial proportion of positive sentiments, indicating that it was viewed as very beneficial to participants. Participants shared that it was most helpful when the nurse care coordinator worked with the patient to identify specific information in the library and highlight it on the participant's dashboard. It may be that the PHN library offered benefits in reducing this overload by curating relevant and clinician-endorsed information.

PHN symptom surveys were designed to increase awareness of symptoms, communicate about symptoms for early intervention, and track progress based on the patient-reported outcomes. Participants found that filling out the PHN symptom surveys was a simple task. They indicated that these surveys prompted them to think about their symptoms and discuss them with the nurse care coordinator who could deliver useful self-management information via the PHN or alert a physician for possible changes in therapy. This finding is aligned with previous studies that reported that tracking and reporting symptoms cause patients to reflect on their own well-being [45]. For those who were undergoing chemotherapy, tracking symptoms in real time increased awareness of self-care and improved communication with the health care team [46]. This also paves the way for the potential to improve clinical outcomes. Basch et al [47] reported that an intervention using Web-based symptom collection, evaluated in a large RCT among patients with cancer, was associated with improved outcomes, including quality-adjusted survival rates, fewer emergency department visits and hospitalizations, and improved quality of life. Thus, the combination of symptom awareness, self-management support, and early intervention shows promise in improving both clinical and person-centered outcomes in cancer care.

PHN messaging features were also viewed positively. Participants expressed the importance of communication outside 
of regular business operating hours. One participant highlighted the stress caused by not being able to communicate with a member of the health care team when experiencing an unfamiliar symptom. Although messages in the PHN were not monitored outside of business hours, there may have been some comfort in being able to express concern at the moment with the confidence that the care coordinator would respond the next morning. In our on-demand information era, consumers have become used to a very quick turnaround on questions and concerns, and this expectation has added urgency when involving a health care concern.

Although participants were willing to use the PHN, difficulties associated with learning something new while sick was a reality. Participants experiencing chemo brain-a term participants used to describe how they feel their thinking is impaired during chemotherapy treatment-emerged as a challenge to adopting new technology or intervention. Even though the need for information resources during initial diagnosis and early treatment may be great, the ability to adopt a tool such as the PHN may be difficult. Future study designs might target caregivers who are actively involved in care coordination. The PHN may also be an aid to survivors who are managing maintenance therapy or a survivorship care plan. In addition, participants did not use the tablet's built-in camera, but some were enthusiastic about trying to show their doctor something (they found concerning on their body) or video chat face-to-face with a care team member. A future study may consider the different preferences of communication routes (eg, telephone, messaging, video conferencing, or virtual reality) when coordinating care.
Perceptions of the usability of the PHN were mixed. Participants made suggestions for improvements in navigation within the app, visual layout and increased font size and graphics, confirmation of tasks completed, and reminders for upcoming tasks. Even in the current environment of ubiquitous access to broadband, participants still reported challenges connecting to the internet (a data plan was provided). Interoperability with the patient portal in the electronic health record was highly preferred. There is room to improve technology to further enhance adoption.

\section{Limitations}

There were several limitations to this study. Participants were recruited from one urban cancer center and were primarily older, white females with a higher socioeconomic status. Interviews were conducted as each participant completed their study period, and the sample size was determined based on an RCT. Coding was conducted after all the interviews were complete. We were not able to add interviews to assure theoretical saturation or explore new avenues of inquiry. Thus, our analysis offers limited perspectives on the usefulness and usability of PHNs.

\section{Conclusions}

This study contributed to expanding the knowledge of cancer care coordination efforts, specifically around incorporating the use of technology to organize information, services, and people. Insight into the patient experience of PHN during chemotherapy provided a better understanding of participants' perceptions of usability and usefulness. Findings from this analysis revealed that participants believed that care coordination is a valuable benefit for cancer patients undergoing chemotherapy, and the use of PHN technology can enhance this process by facilitating better communication and access to information.

\section{Acknowledgments}

This study was funded by the McKesson Foundation (JJ and KK, principal investigators), a grant from Boston University Center for the Future of Technology in Cancer Care (KK, principal investigator) via the National Institute of Biomedical Imaging and Bioengineering Award U54EB015403 (Catherine M Klapperich, center principal investigator), and a Gordon and Betty Moore Foundation grant to the Betty Irene Moore School of Nursing to fund graduate student researchers (VN and CM). The authors thank Chelsie Marie Gonzales Antonio, RN, Thuy B Le, and Ronald Grummer for help with the recruitment of participants for this study. The authors thank Phillip Bautista and Nicole Mahr for assisting with the participant interviews. Finally, the authors thank Drs Theresa H Keegan, Brian A Jonas, Elizabeth I Rice, and Sheryl L Catz for providing thoughtful feedback on drafts of the manuscript.

\section{Conflicts of Interest}

None declared.

\section{Multimedia Appendix 1}

Exemplar quotations for themes.

[DOCX File, 29 KB-Multimedia Appendix 1]

\section{Multimedia Appendix 2}

Exemplar quotations of the usefulness of the Personal Health Network features. [DOCX File, $28 \mathrm{~KB}-$ Multimedia Appendix 2]

\section{References}


1. Institute of Medicine, Board on Health Care Services, Committee on Improving the Quality of Cancer Care: Addressing the Challenges of an Aging Population. In: Levit L, Balogh E, Nass S, Ganz PA, editors. Delivering High-quality Cancer Care: Charting A New Course For A System In Crisis. Washington, DC: National Academies Press; 2014.

2. Ganz PA, Levit LA. Charting a new course for the delivery of high-quality cancer care. J Clin Oncol 2013 Dec 20;31(36):4485-4487. [doi: 10.1200/jco.2013.53.7993]

3. Ganz PA. Delivering patient-centered care in the setting of advanced cancer: what does a clinical risk-prediction model have to do with it? JAMA Oncol 2015 Jul 1;1(4):430-432. [doi: 10.1001/jamaoncol.2015.0832] [Medline: 26181248]

4. Balogh EP, Ganz PA, Murphy SB, Nass SJ, Ferrell BR, Stovall E. Patient-centered cancer treatment planning: improving the quality of oncology care. Summary of an institute of medicine workshop. Oncologist 2011 Nov 29;16(12):1800-1805 [FREE Full text] [doi: 10.1634/theoncologist.2011-0252] [Medline: 22128118]

5. Schoen C, Osborn R, Squires D, Doty M, Pierson R, Applebaum S. New 2011 survey of patients with complex care needs in eleven countries finds that care is often poorly coordinated. Health Aff (Millwood) 2011 Dec;30(12):2437-2448. [doi: 10.1377/hlthaff.2011.0923] [Medline: 22072063]

6. Institute of Medicine, Committee on Quality of Health Care in America. Crossing The Quality Chasm: A New Health System For The 21st Century. Washington, DC: National Academies Press; 2001.

7. Lamé G, Jouini O, Stal-Le Cardinal J. Outpatient chemotherapy planning: a literature review with insights from a case study. IIE Trans Healthc Syst Eng 2016 May 31;6(3):127-139. [doi: 10.1080/19488300.2016.1189469]

8. US Department of Health and Human Services. Agency for Healthcare Research and Quality. 2013. 2013 Annual Progress Report to Congress: National Strategy for Quality Improvement in Health Care URL: https://www.ahrq.gov/workingforquality/ reports/2013-annual-report.html [accessed 2020-01-01]

9. Kim KK, Bell JF, Reed SC, Whitney RL. Coordination at the point of need. In: Hesse BW, Ahern D, Beckjord E, editors. Oncology Informatics: Using Health Information Technology To Improve Processes And Outcomes In Cancer. Cambridge, Massachusetts: Academic Press; 2016:81-100.

10. Vandyk AD, Harrison MB, Macartney G, Ross-White A, Stacey D. Emergency department visits for symptoms experienced by oncology patients: a systematic review. Support Care Cancer 2012 Aug;20(8):1589-1599. [doi: 10.1007/s00520-012-1459-y] [Medline: 22526151]

11. Peikes D, Chen A, Schore J, Brown R. Effects of care coordination on hospitalization, quality of care, and health care expenditures among medicare beneficiaries: 15 randomized trials. J Am Med Assoc 2009 Feb 11;301(6):603-618. [doi: 10.1001/jama.2009.126] [Medline: 19211468]

12. Arora NK, Jensen RE, Sulayman N, Hamilton AS, Potosky AL. Patient-physician communication about health-related quality-of-life problems: are non-Hodgkin lymphoma survivors willing to talk? J Clin Oncol 2013 Nov 1;31(31):3964-3970 [FREE Full text] [doi: 10.1200/JCO.2012.47.6705] [Medline: 24062408]

13. Walsh J, Young J, Harrison J, Butow P, Solomon M, Masya L, et al. What is important in cancer care coordination? A qualitative investigation. Eur J Cancer Care (Engl) 2011 Mar;20(2):220-227. [doi: 10.1111/j.1365-2354.2010.01187.x] [Medline: 20477854]

14. Hoerger M, Epstein RM, Winters PC, Fiscella K, Duberstein PR, Gramling R, et al. Values and options in cancer care (VOICE): study design and rationale for a patient-centered communication and decision-making intervention for physicians, patients with advanced cancer, and their caregivers. BMC Cancer 2013 Apr 9;13(1):188 [FREE Full text] [doi: 10.1186/1471-2407-13-188] [Medline: 23570278]

15. Hesse BW, Beckjord E, Rutten LJ, Fagerlin A, Cameron LD. Cancer communication and informatics research across the cancer continuum. Am Psychol 2015;70(2):198-210. [doi: 10.1037/a0036852] [Medline: 25730725]

16. Beckjord EB, Arora NK, McLaughlin W, Oakley-Girvan I, Hamilton AS, Hesse BW. Health-related information needs in a large and diverse sample of adult cancer survivors: implications for cancer care. J Cancer Surviv 2008 Sep;2(3):179-189. [doi: 10.1007/s11764-008-0055-0] [Medline: 18792791]

17. Klasnja P, Hartzler A, Powell C, Pratt W. Supporting cancer patients' unanchored health information management with mobile technology. AMIA Annu Symp Proc 2011;2011:732-741 [FREE Full text] [Medline: 22195130]

18. Hesse BW, Hanna C, Massett HA, Hesse NK. Outside the box: will information technology be a viable intervention to improve the quality of cancer care? J Natl Cancer Inst Monogr 2010;2010(40):81-89 [FREE Full text] [doi: 10.1093/jncimonographs/lgq004] [Medline: 20386056]

19. Mortimer L, Strawbridge L, Lukens E, Bassano A, Conway P, Kline R. Centers for Medicare \& Medicaid Services' oncology care model: delivering higher value cancer care. Clin Pharmacol Ther 2017 May;101(5):569-571. [doi: 10.1002/cpt.638] [Medline: 28139833]

20. Dickinson R, Hall S, Sinclair JE, Bond C, Murchie P. Using technology to deliver cancer follow-up: a systematic review. BMC Cancer 2014 May 3;14:311 [FREE Full text] [doi: 10.1186/1471-2407-14-311] [Medline: 24885758]

21. Akter S, Ray P. mHealth - an ultimate platform to serve the unserved. Yearb Med Inform 2010;19(1):94-100. [doi: 10.1055/s-0038-1638697] [Medline: 20938579]

22. Free C, Phillips G, Galli L, Watson L, Felix L, Edwards P, et al. The effectiveness of mobile-health technology-based health behaviour change or disease management interventions for health care consumers: a systematic review. PLoS Med 2013;10(1):e1001362 [FREE Full text] [doi: 10.1371/journal.pmed.1001362] [Medline: 23349621] 
23. Davis SW, Oakley-Girvan I. mHealth education applications along the cancer continuum. J Cancer Educ 2015 Jun;30(2):388-394. [doi: 10.1007/s13187-014-0761-4] [Medline: 25482319]

24. Kim K, Bell J, Reed S, Joseph J, Bold R, Cerrone K, et al. A Novel Personal Health Network for Patient-centered Chemotherapy Care Coordination. In: Proceedings of the International Conference on Collaboration Technologies and Systems. 2014 Presented at: CTS'14; May 19-23, 2014; Minneapolis, MN, USA. [doi: 10.1109/cts.2014.6867603]

25. Kim K, Bell J, Bold R, Davis A, Ngo V, Reed S, et al. A personal health network for chemotherapy care coordination: evaluation of usability among patients. Stud Health Technol Inform 2016;225:232-236. [doi: 10.3233/978-1-61499-658-3-232] [Medline: 27332197]

26. Venkatesh V, Thong JY, Xu X. Consumer acceptance and use of information technology: extending the unified theory of acceptance and use of technology. Manag Inf Syst Q 2012;36(1):157. [doi: 10.2307/41410412]

27. Saldaña J. The Coding Manual For Qualitative Researchers. London: Sage Publications Ltd; 2015.

28. Miles M, Huberman A, Saldaña J. Qualitative Data Analysis: A Methods Sourcebook. Thousand Oaks, California: Sage Publications, Inc; 2014.

29. León MC, Nieto-Hipólito JI, Garibaldi-Beltrán J, Amaya-Parra G, Luque-Morales P, Magaña-Espinoza P, et al. Designing a model of a digital ecosystem for healthcare and wellness using the business model canvas. J Med Syst 2016 Jun;40(6):144. [doi: 10.1007/s10916-016-0488-3] [Medline: 27118010]

30. Iyawa GE, Herselman M, Botha A. Digital health innovation ecosystems: from systematic literature review to conceptual framework. Procedia Comput Sci 2016;100:244-252. [doi: 10.1016/j.procs.2016.09.149]

31. Iyawa GE, Herselman M, Botha A. A Scoping Review of Digital Health Innovation Ecosystems in Developed and Developing Countries. In: Proceedings of the 2017 IST-Africa Week Conference. 2017 Presented at: IST-Africa'17; May 30-June 2, 2017; Windhoek, Namibia. [doi: 10.23919/istafrica.2017.8102325]

32. Marcos-Pablos S, García-Peñalvo FJ. Technological ecosystems in care and assistance: a systematic literature review. Sensors (Basel) 2019 Feb 9;19(3):708 [FREE Full text] [doi: 10.3390/s19030708] [Medline: 30744096]

33. Davis SW, Oakley-Girvan I. Achieving value in mobile health applications for cancer survivors. J Cancer Surviv 2017 Aug;11(4):498-504. [doi: 10.1007/s11764-017-0608-1] [Medline: 28342093]

34. Kim KK, Bell JF, Boicey C, Freeman-Daily J, Hull S, McCollister-Slipp A, et al. A Framework for Person-Centered, Community-Wide Care Coordination. In: Proceedings of the 2015 AMIA Annual Symposium Proceedings Archive. Washington, DC: American Medical Informatics Association; 2015 Presented at: AMIA'15; November 14-18, 2015; San Francisco, California p. 78-79 URL: https://knowledge.amia.org/59310-amia-1.2741865/t001-1.2745946/f001-1.2745947/ 2247697-1.2746098/2247697-1.2746099?qr=1

35. Maguire R, Ream E, Richardson A, Connaghan J, Johnston B, Kotronoulas G, et al. Development of a novel remote patient monitoring system: the advanced symptom management system for radiotherapy to improve the symptom experience of patients with lung cancer receiving radiotherapy. Cancer Nurs 2015;38(2):E37-E47. [doi: 10.1097/NCC.0000000000000150] [Medline: 24836956]

36. Larsen M, Rowntree J, Young A, Pearson S, Smith J, Gibson O, et al. Chemotherapy side-effect management using mobile phones. Conf Proc IEEE Eng Med Biol Soc 2008;2008:5152-5155. [doi: 10.1109/IEMBS.2008.4650374] [Medline: 19163877]

37. Baseman J, Revere D, Baldwin L. A mobile breast cancer survivorship care app: pilot study. JMIR Cancer 2017 Sep 26;3(2):e14 [FREE Full text] [doi: 10.2196/cancer.8192] [Medline: 28951383]

38. Gorin SS, Haggstrom D, Han PKJ, Fairfield KM, Krebs P, Clauser SB. Cancer care coordination: a systematic review and meta-analysis of over 30 years of empirical studies. Ann Behav Med 2017 Aug;51(4):532-546. [doi: 10.1007/s12160-017-9876-2] [Medline: 28685390]

39. Papadakos J, Trang A, Cyr AB, Abdelmutti N, Giuliani ME, Snow M, et al. Deconstructing cancer patient information seeking in a consumer health library toward developing a virtual information consult for cancer patients and their caregivers: a qualitative, instrumental case study. JMIR Cancer 2017 May 24;3(1):e6 [FREE Full text] [doi: 10.2196/cancer.6933] [Medline: 28539305]

40. Hesse BW, Arora NK, Beckjord EB, Rutten LJ. Information support for cancer survivors. Cancer 2008 Jun 1;112(11 Suppl):2529-2540 [FREE Full text] [doi: 10.1002/cncr.23445] [Medline: 18428201]

41. Roach A, Lykins E, Gochett C, Brechting E, Graue L, Andrykowski M. Differences in cancer information-seeking behavior, preferences, and awareness between cancer survivors and healthy controls: a national, population-based survey. J Cancer Educ 2009;24(1):73-79 [FREE Full text] [doi: 10.1080/08858190802664784] [Medline: 19259869]

42. Mukherjee A, Bawden D. Health information seeking in the information society. Health Info Libr J 2012 Sep;29(3):242-246 [FREE Full text] [doi: 10.1111/j.1471-1842.2012.00997.x] [Medline: 22925387]

43. Clarke MA, Moore JL, Steege LM, Koopman RJ, Belden JL, Canfield SM, et al. Health information needs, sources, and barriers of primary care patients to achieve patient-centered care: a literature review. Health Informatics J 2016 Dec;22(4):992-1016. [doi: 10.1177/1460458215602939] [Medline: 26377952]

44. Fiordelli M, Diviani N, Schulz PJ. Mapping mhealth research: a decade of evolution. J Med Internet Res 2013 May 21;15(5):e95 [FREE Full text] [doi: 10.2196/jmir.2430] [Medline: 23697600] 
45. Langius-Eklöf A, Christiansen M, Lindström V, Blomberg K, Nyman MH, Wengström Y, et al. Adherence to report and patient perception of an interactive app for managing symptoms during radiotherapy for prostate cancer: descriptive study of logged and interview data. JMIR Cancer 2017 Oct 31;3(2):e18 [FREE Full text] [doi: 10.2196/cancer.7599] [Medline: 29089290]

46. Breen S, Ritchie D, Schofield P, Hsueh Y, Gough K, Santamaria N, et al. The Patient Remote Intervention and Symptom Management System (PRISMS) - a Telehealth- mediated intervention enabling real-time monitoring of chemotherapy side-effects in patients with haematological malignancies: study protocol for a randomised controlled trial. Trials 2015 Oct 19;16:472 [FREE Full text] [doi: 10.1186/s13063-015-0970-0] [Medline: 26481873]

47. Basch E, Deal AM, Kris MG, Scher HI, Hudis CA, Sabbatini P, et al. Symptom monitoring with patient-reported outcomes during routine cancer treatment: a randomized controlled trial. J Clin Oncol 2016 Feb 20;34(6):557-565 [FREE Full text] [doi: 10.1200/JCO.2015.63.0830] [Medline: 26644527]

\title{
Abbreviations \\ mHealth: mobile health \\ PHN: Personal Health Network \\ RCT: randomized controlled trial
}

\author{
Edited by G Eysenbach; submitted 07.12.19; peer-reviewed by GE Iyawa, T Muto; comments to author 19.01.20; revised version \\ received 30.01.20; accepted 01.02.20; published 26.05.20 \\ Please cite as: \\ Ngo V, Matsumoto CG, Joseph JG, Bell JF, Bold RJ, Davis A, Reed SC, Kim KK \\ The Personal Health Network Mobile App for Chemotherapy Care Coordination: Qualitative Evaluation of a Randomized Clinical \\ Trial \\ JMIR Mhealth Uhealth 2020;8(5):e16527 \\ URL: http://mhealth.jmir.org/2020/5/e16527/ \\ doi: $\underline{10.2196 / 16527}$ \\ PMID: 32452814
}

(C) Victoria Ngo, Cynthia G Matsumoto, Jill G Joseph, Janice F Bell, Richard J Bold, Andra Davis, Sarah C Reed, Katherine K Kim. Originally published in JMIR mHealth and uHealth (http://mhealth.jmir.org), 26.05.2020. This is an open-access article distributed under the terms of the Creative Commons Attribution License (https://creativecommons.org/licenses/by/4.0/), which permits unrestricted use, distribution, and reproduction in any medium, provided the original work, first published in JMIR mHealth and uHealth, is properly cited. The complete bibliographic information, a link to the original publication on http://mhealth.jmir.org/, as well as this copyright and license information must be included. 